\title{
Mitotic inactivation of a human SWI/SNF chromatin remodeling complex
}

\author{
Saïd Sif, ${ }^{1,2}$ P. Todd Stukenberg, ${ }^{3}$ Marc W. Kirschner, ${ }^{3}$ and Robert E. Kingston ${ }^{1,2,4}$ \\ ${ }^{1}$ Department of M olecular Biology, M assachusetts General Hospital, Boston, Massachusetts 02114 USA; ${ }^{2}$ Department \\ of Genetics and ${ }^{3}$ Department of Cell Biology, Harvard M edical School, Boston, Massachusetts 02115 USA
}

\begin{abstract}
During mitosis, chromatin is condensed into mitotic chromosomes and transcription is inhibited, processes that might be opposed by the chromatin remodeling activity of the SWI/SNF complexes. Brgl and hBm, which are components of human SWI/SNF (hSWI/SNF) complexes, were recently shown to be phosphorylated during mitosis. This suggested that phosphorylation might be used as a switch to modulate SWI/ SNF activity. Using an epitopetag strategy, we have purified hSWI/SNF complexes at different stages of the cell cycle, and found that $h S W I$ / SNF was inactive in cells blocked in $G_{2}-$ M. Mitotic $h S W l$ / SNF contained Brgl but not hBrm, and was phosphorylated on at least two subunits, hSWI3 and Brgl. In vitro, active hSWI/SNF from asynchronous cells can be phosphorylated and inactivated by ERK1, and reactivated by dephosphorylation. hSWI/SNF isolated as cells traversed mitosis regained activity when its subunits were dephosphorylated either in vitro or in vivo. We propose that this transitional inactivation and reactivation of $\mathrm{hSWl} / \mathrm{SNF}$ is required for formation of a repressed chromatin structure during mitosis and reformation of an active chromatin structure as cells leave mitosis.
\end{abstract}

[Key Words: SWI/SN F complex; nucleosomes; phosphorylation; mitosis; chromatin]

Received July 10, 1998; revised version accepted July 31, 1998.

Regulation of gene expression occurs in the context of chromatin, whose structure inhibits transcription at different levels including activator binding, preinitiation complex formation, and transcription elongation (for review, see Paranjape et al . 1994; Kingston et al. 1996). The inhibitory effects of chromatin structure on transcription factor function can be alleviated by ATP-dependent remodeling complexes, which include two major classes: complexes that contain the SWI2/SN F2 family of proteins (SWI/SNF and RSC), and ISWI-containing complexes (NURF, ACF, and CHRAC).

All of these remodeling complexes contain a highly conserved subunit that is related to the yeast SWI2/ SN F2 protein, which harbors a DNA-dependent ATPase domain (Laurent et al. 1992; Tamkun et al. 1992; Khavari et al. 1993; M uchardt and Yaniv 1993; Chiba et al. 1994). In yeast, the highly related proteins, SWI2/SNF2 and STH1, are part of two distinct remodeling complexes designated SWI/SN F and RSC, respectively (Cairns et al. 1994, 1996; Peterson et al. 1994). In Drosophila, a SWI2/ SN F2 homolog termed brahma (Tamkun et al. 1992) is associated with a SN F5-related protein (Snrl) in a large multisubunit complex (Dingwall et al. 1995). A second Drosophila ATPase-containing protein, designated I-SWI (imitation switch), has been shown to be part of at least three different complexes, NURF, ACF, and CHRAC

${ }^{4}$ Corresponding author.

E-MAIL kingston@frodo.mgh.harvard.edu; FAX (617) 726-5949.
(Tsukiyama and Wu 1995; Ito et al . 1997; Varga-Weisz et al. 1997). In humans, two separate nucl eosome remodeling complexes have been isolated that contain the highly related ATPases, Brgl and hBrm (Kwon et al. 1994; Wang et al. 1996a,b). These complexes are collectively referred to as the human SWI/SNF complexes. The yeast and human SWI2/SNF2-family complexes, and the Drosophila I-SWI-containing complexes have all been purified and shown to al ter nucleosome structure in vitro in an ATP-dependent manner (C ôté et al. 1994; Kwon et al. 1994; Tsukiyama and Wu 1995; Ito et al. 1997; VargaWeisz et al. 1997).

Different members of the SWI/SN F family of proteins have been shown to be involved in regulating cell growth and proliferation. Two subunits of the yeast RSC compl ex, ST H 1 and SFH1, a SN F5 paralog, are both essential for viability (Laurent et al. 1992; Cao et al. 1997). In contrast, the genes encoding the yeast SWI/SN F complex are not essential for mitotic growth under certain growth conditions (for review, see Winston and Carlson 1992). The role of Brgl in controlling cell growth in mammals has been el ucidated by gene targeting experiments. Inactivation of both alleles of Brgl in murine F9 cells leads to cell death; however, when a human Brgl cDNA is stably expressed in these cells prior to the inactivation of both endogenous alleles, cells are able to proliferate (Sumi-Ichinose et al . 1997). This suggests that Brgl is essential for viability, and further suggests that the function of both RSC and the Brgl-based hSWI/SN F 
complexes is essential for cell growth and viability (Laurent et al. 1992; Cairns et al. 1996; Cao et al. 1997).

Other studies in human cells have shown that Brgl and $\mathrm{hBrm}$ can interact with the retinoblastoma family of tumor suppressors, and consequently induce cell-cycle arrest (Dunai ef et al. 1994; Strober et al. 1996). M oreover, analysis of Brgl and hBrm during the cell cycle revealed that both proteins undergo phosphorylation on entry into mitosis, and although the level of Brgl remains constant, hBrm appears to be degraded during mitosis (Muchardt et al. 1996; Reyes et al . 1997). Taken together, these results suggest that some of the components of hSWI/SNF complexes are involved in regulating cell growth, and that their activities are regulated in a cellcycle dependent manner.

During mitosis, newly replicated interphasic chromatin is condensed into mitotic chromosomes, and many proteins are phosphorylated by specific cyclin-dependent kinases (for review, see N asmyth 1996; Dynlacht 1997). These changes contribute to the abrupt and general inhibition of transcription during mitosis (for review, see Gottesfeld and Forbes 1997). Mitotic inhibition of gene expression is likely to be caused in part by altering the activity of general transcri pti on factors (Hartl et al. 1993; White et al. 1995; Segil et al. 1996). Other mechanisms for mitotic inhibition of transcription might involve inactivation of gene-specific transcriptional activators (Lüscher and Eisenman 1992), and di splacement of these factors from mitotic chromatin (Martinez-Bal bás et al. 1995). It might also be important to inactivate remodeling activities during mitosis to allow the tight compaction of DNA. Moreover, a mechanism that reversibly inactivated chromatin remodel ing complexes during mitosis could prevent these activities from interfering with the processes that direct chromatin condensation. The cell cycle-dependent phosphorylation of Brgl and hBrm discussed above suggested the possibility that the activity of hSWI/SNF complexes might be regulated in this manner. To address this hypothesis, we devel oped a cell line that can be used to rapidly purify hSWI/SN F complexes at different stages of the cell cycle. We show here that the hSWI/SNF complexes are reversibly inactivated by phosphorylation as cells traverse mitosis.

\section{Results}

\section{Purification of Flag-tagged hSWI/SNF complexes}

To purify homogeneous hSWI/SN F complex with high specific activity, we used a hel per-free retrovirus system to establish a cell line that expresses an epitope-tagged copy of Ini 1, which is the human homol og of yeast SN F5 protein (Kal pana et al. 1994). This strategy has been used previously to immunopurify multisubunit complexes (Zhou et al. 1992). We used the Inil gene because attempts to establish cell lines with retrovirally transduced tagged versions of Brgl or hBrm resulted in cells that grew very slowly (data not shown). In human cells, Inil is thus far the only SN F5 homolog found in association with either Brgl- or hBrm-containing hSWI/SN F complexes (Wang et al. 1996a,b). HeLa S3 clones expressing varying levels of carboxy-terminally Flag-tagged Ini 1 (FL-Ini1) were analyzed by Western blotting using an anti-Flag M 2 antiserum that recognizes the Flag-tag epitope (data not shown), and clone FL-Ini1-11 which expresses high levels of FL-Inil was selected for further characterization.

Previously, SNF5 has been shown to be a subunit of the yeast SWI/SN F complex, and more recently theyeast SN F5 homolog, SFH1, has been found to be part of the RSC complex (Cairns et al. 1994; Peterson et al. 1994; Cao et al. 1997). To determine whether the tagged Ini 1 could interact with endogenous Brgl and hBrm, we performed coimmunoprecipitation experiments, and found that FL-Inil can form complexes with both Brgl and hBrm (data not shown, and see below).

To purify hSWI/SN F complexes, we developed a twostep purification scheme using the FL-Inil-11 cell line (Fig. 1A). N uclear extracts were incubated with anti-Flag M2 affinity gel, and after extensive washing with buffers containing increasing salt concentrations, the affinity column was eluted with buffer containing Flag peptide. Using antibodies specific to cloned hSWI/SNF subunits, we were able to detect the presence of Brgl, hBrm, hSWI3, and FL-Ini1 in the eluate (Fig. 1B, lane M2).

$\mathbf{A}$

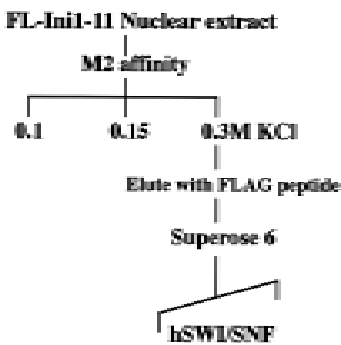

B

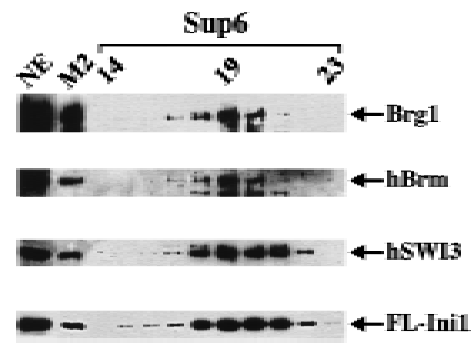

Figure 1. Purification of proteins associated with Flag-tagged Ini 1. (A) Purification of Flag-tagged hSWI/SN F complexes. FLIni1-11 nuclear extracts were incubated with anti-Flag M 2 affinity gel, and after several washes with buffer containing increasing amounts of salt, the proteins retained on the affinity column were eluted with buffer containing 20 -fold molar excess of Flag peptide. Eluted proteins were then fractionated on a Superose 6 sizing column. (B) hSWI/SN F subunits cofractionate with FL-Ini 1. Western bl ot analysis was performed with $50 \mu \mathrm{g}$ of nuclear extract (NE); $1.2 \mu \mathrm{g}$ of affinity purified SWI/SNF fraction (M 2), and $15 \mu \mathrm{l}$ of sizing column fractions 14-23 [Superose 6 (Sup6)]. 
Analysis of this fraction by SDS-PAGE demonstrated that it contained several prominent bands of the same size as hSWI/SN F subunits (arrows, Fig. 2A, lane 1). The

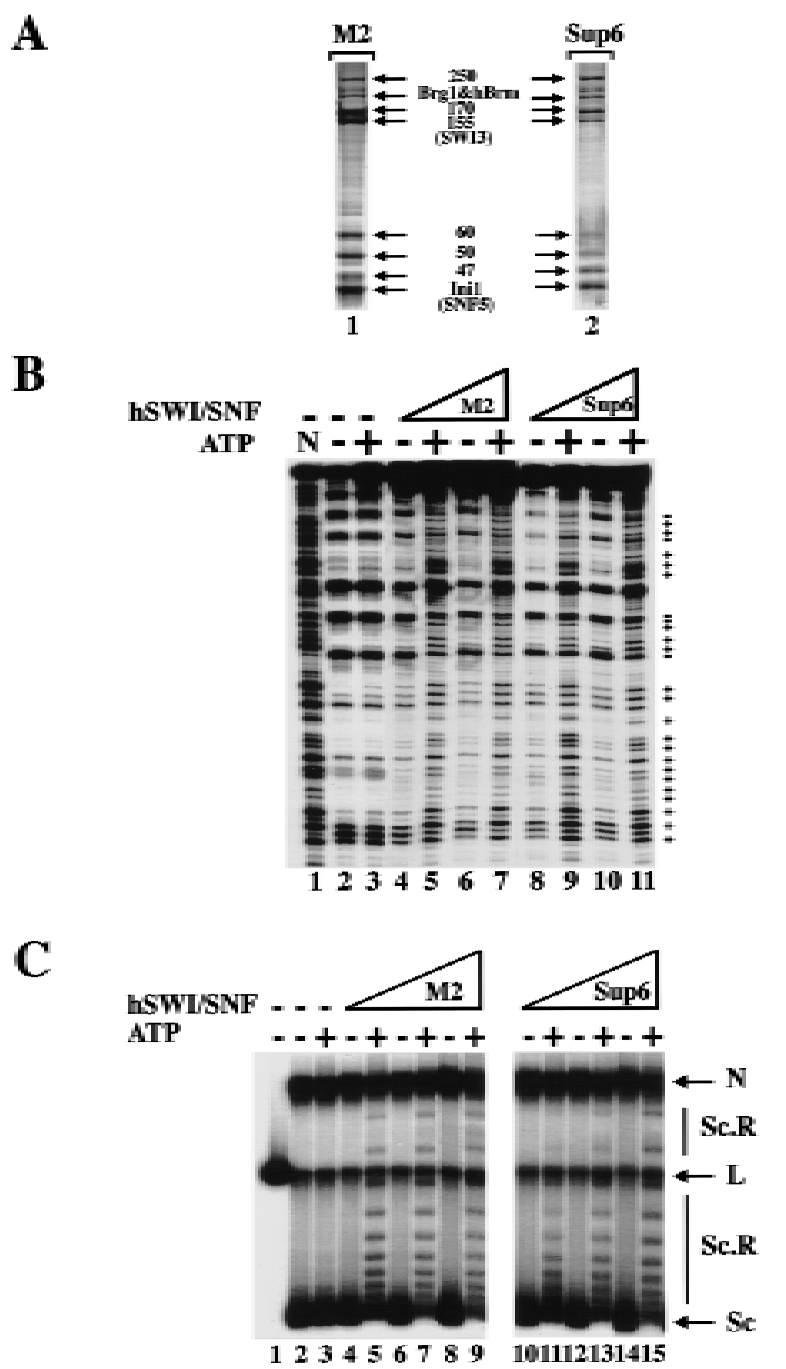

Figure 2. Biochemical characterization of Flag-tagged hSWI/ SNF complexes. (A) Amounts of $560 \mathrm{ng}$ of affinity-purified hSWI/SN F (M2, lane 1) and 465 ng of sizing column fraction Superose 6 (sup6), lane 2] were analyzed by SDS-PAGE, and proteins were visual ized by silver staining. (B) N ucleosome disrupting activity. Either $280 \mathrm{ng}$ (lanes 4,5 ) or $560 \mathrm{ng}$ (lanes 6,7) of M2 fractions was incubated with mononucleosomes with or without ATP. Similarly, $155 \mathrm{ng}$ (lanes 8,9) and $310 \mathrm{ng}$ (lanes $10,11)$ of Sup6 peak fractions were incubated with core particles as indicated. As a control, naked DNA ( $\mathrm{N}$, lane 1 ) and nucleosomal DNA with or without ATP (Ianes 2,3) are shown. Symbols at right indicate the changes to DN ase sensitivity caused by $\mathrm{hSWI} / \mathrm{SNF}$ in an ATP-dependent manner. (C) Remodeling activity on nucleosomal arrays. Increasing amounts of either M 2: 19 ng (lanes 4,5), 56 ng (lanes 6,7), 84 ng (lanes 8,9), or Sup6 fractions: $10 \mathrm{ng}$ (lanes 10,11), 31 ng (lanes 12,13), 62 ng (lanes $14,15)$, were incubated with $8 \mathrm{ng}$ of assembled chromatin templates with or without ATP as indicated. (Lane 1) Linear plasmid DNA (lanes 2,3) assembled template incubated with or without ATP. The resolved DN A templates are supercoiled (Sc); relaxed and supercoiled (Sc.R); linear (L); and nicked (N). affinity fractionated hSWI/SN F complexes were further purified by gel filtration through a Superose 6 sizing column (Fig. 1A). The Brgl, hBrm, hSWI3, and FL-Inil proteins all cofractionated on this column (Fig. 1B). The resultant peak fractions contained nine polypeptides with the characteristic mobility of hSWI/SN F components (arrowheads, Fig. 2A, lane 2). Brgl and hBrm are believed to form two distinct complexes, each of which contains the other seven indicated subunits (Kwon et al. 1994; Wang et al. 1996a,b). Therefore, we conclude that the FL-Ini 1-11 cell line can be used to isolate both the hBrm and the Brgl-based hSWI/SN F complexes.

\section{Biochemical characterization of Flag-tagged hSWI/SNF complexes}

To determine whether Flag-tagged hSWI/SN F complexes are active, we tested their ability to disrupt nucleosomal core particles (Fig. 2B). When M 2 immunoaffinity column fractions were added to the reactions without ATP, there was no significant change in the digestion pattern of nucleosomes (Fig. 2B, lanes 4,6). When ATP was added, disruption of the DNase I pattern was observed (lanes 5,7), and this activity was maximal at a fourfold ratio of hSWI/SNF to nucleosomes (cf. lanes 5 and 7). Similar activity at the same molar ratios was seen with the Superose 6-purified hSWI/SNF (lanes 8-11).

Human SWI/SNF has been shown to efficiently alter the topology of DNA templates that have been assembled into arrays of nucleosomes (Kwon et al. 1994). When the hSWI/SN F fractions tested above were incubated with templates that had been assembled into nucleosomes by use of Drosophila embryo extracts (Bulger and Kadonaga 1994), there was no change in the topol ogy of the plasmid DN A in the absence of ATP (Fig. 2C). However, when ATP was added, the topology of the templates changed, as shown by the decrease in the amount of rapidly migrating DNA and the increase in intermediate species that contain fewer negative supercoils. In this assay, both immunopurified and superose 6 fractions were able to remodel chromatin templates at molar ratios of considerably less than one SWI/SNF complex per nucleosome, showing that these fractions are highly active.

hSWI/SNF nucl eosome-disrupting activity is inhibited during mitosis

To examine the subunit composition and nucleosomal disrupting activity of hSWI/SN F complexes during the course of the cell cycle, we used the epitope-tagged Ini 1 cell line. Cells were blocked either at S phase $(90 \%$ of cells were blocked as estimated by flow cytometry) or $\mathrm{G}_{2}-\mathrm{M}$ phase (94\% block) by treatment with hydroxyurea or nocodazole, respectively, and extracts from these cells and from exponentially growing cells (mitotic index $<20 \%$ ) were prepared. Blocking cells at $\mathrm{G}_{2}-\mathrm{M}$ by nocodazole treatment has been shown to result in phosphorylation of $\mathrm{Brgl}$ and $\mathrm{hBrm}$, and partial degradation of hBrm (M uchardt et al. 1996; Reyes et al. 1997). We re- 
produced this observation using Western analysis (Fig. 3A). The levels of both proteins remained constant in asynchronous cells and cells blocked at $S$ phase. However, in cells blocked at $\mathrm{G}_{2}-\mathrm{M}, \mathrm{Brgl}$ migrated with a reduced mobility on SDS-polyacrylami de gels, and hBrm was not detected. Furthermore, when we tested two other subunits, hSWI3 and FL-Ini1, we discovered that hSWI3 also had a slower mobility and the levels of both hSWI3 and Ini 1 were slightly reduced in cells blocked at $\mathrm{G}_{2}-\mathrm{M}$ (Fig. 3A). Treatment of $\mathrm{G}_{2}-\mathrm{M}$ extract with alkaline phosphatase increased the mobility of both Brgl and hSWI3, indicating that the change in mobility of Brgl

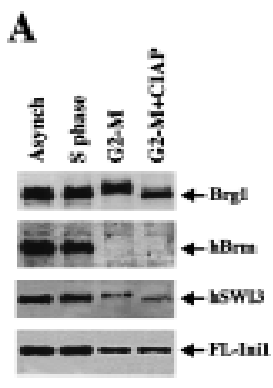

C

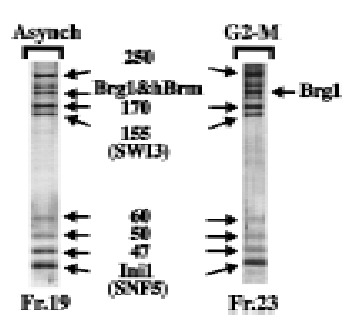

B

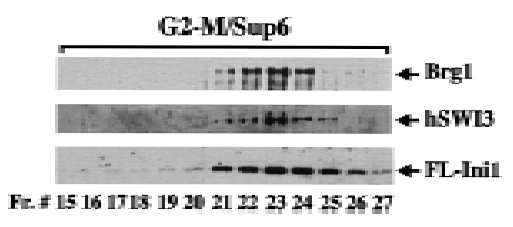

D)
Figure 3. Mitotic hSWI/SNF is phosphorylated and lacks nucleosome disrupting activity. (A) hSWI/SNF subunits are regulated differently during mitosis. Approximately $10 \mu \mathrm{g}$ of total protein from exponentially growing cells (Asynch), cells blocked in S phase (S phase), or cells blocked in prometaphase $\left(G_{2}-M\right)$ were analyzed by Western blotting with anti-Brgl, antihBrm, anti-hSWI3, or anti-Flag antiserum. Where indicated, proteins were incubated with 10-20 units of calf alkaline phosphatase (CIAP) for $45 \mathrm{~min}$ at $37^{\circ} \mathrm{C}$. (B) Mitotic hSWI/SN F subunits cofractionate through Superose 6 (Sup6) sizing column. Western blot analysis of Sup6 column fractions (fr.) 15-27, with anti-Brgl, anti-hSWI3, and anti-Flag antisera. Mitotic hSWI/ SN F subunits consistently $(n=4)$ eluted later (fr. 23) than the asynchronous complex (fr. 19). (C) M itotic hSWI/SN F complex is intact. Equal amounts of hSWI/SNF sizing column peak fractions ( $500 \mathrm{ng})$ from either exponentially growing cells (A synch, fr. 19), or cells blocked in early mitosis $\left(G_{2}-M\right.$, fr. 23) were analyzed by SDS-PAGE and silver staining. (D) Phosphatase treatment of mitotic hSWI/SN F enables the complex to disrupt mononucleosomes. Similar amounts of Sup6 fractions from either asynchronous cells ( $500 \mathrm{ng}$ ) or cells blocked in $\mathrm{G}_{2}-\mathrm{M}$ (560 ng) were incubated with mononucleosomes with or without ATP and CIAP as indicated. and hSWI3 was caused by phosphorylation of these proteins in the $\mathrm{G}_{2}-\mathrm{M}$ extracts.

We examined the integrity of the hSWI/SNF complexes isolated at various stages of the cell cycle by using immunoaffinity fractionation on an anti-Flag M2 column. Analysis by silver staining of the proteins purified from asynchronous, S-phase or $\mathrm{G}_{2}-\mathrm{M}$ extracts showed that their polypeptide composition was grossly similar, suggesting that hSWI/SNF complexes remained intact at different stages of the cell cycle (data not shown and see below). Activity of these fractions was tested by use of mononucleosome disruption assays (data not shown and see below). hSWI/SNF complexes from either asynchronous cells or cells bl ocked at S phase were able to disrupt nucleosomal core particles to the same extent in an ATP-dependent manner. However, when hSWI/SN F complex purified from cells arrested at $G_{2}-M$ was used in this assay, DN ase I activity was inhibited, and no significant ATP-dependent effects were observed.

We further purified hSWI/SN $F$ from the $G_{2}-M$ phase using a Superose 6 sizing colum (Fig. 3B), and compared it with $\mathrm{hSWI} / \mathrm{SNF}$ purified in the same manner from asynchronous cells. The activity in the $\mathrm{G}_{2}-\mathrm{M}$ preparation that inhibits DN ase I el uted at a larger apparent size (fr. 19) than the hSWI/SN F subunits on this column (data not shown), and therefore was not pursued further in this work. The hSWI/SNF complex purified from $\mathrm{G}_{2}-\mathrm{M}$ had a composition similar to that of the complex purified from asynchronous cells (Fig. 3B,C), and eluted at a smaller apparent native molecular weight than the asynchronous complex on an equival ent Superose 6 column (mitotic hSWI/SNF subunits peak at fr. 23, Fig. 3B and asynchronous hSWI/SN F peaks at fr. 19, Fig. 1B). However, unlike hSWI/SNF purified from asynchronous cells, mitotic hSWI/SN F lacks nucleosome remodeling activity in the presence of ATP (Fig. 3D, cf. Iane 6 with lane 2). When both asynchronous and mitotic hSWI/SN F fractions were treated with alkaline phosphatase, however, they were both able to alter nucl eosome structure in the presence of ATP (Fig. 3D, cf. lanes 4 and 8 with lane 2). Taken together, these findings show that phosphorylated hSWI/SNF isolated from cells at $\mathrm{G}_{2}-\mathrm{M}$ is inactive, and that dephosphorylation restores its nucleosome remodeling activity.

hSWI/SNF complex is reactivated as cells exit mitosis

To examine when hSWI/SN F regained activity, we carried out a detailed analysis of its activity as cells exit mitosis. Cell were synchronized with nocodazole in $\mathrm{G}_{2}{ }^{-}$ $M$, and then were rel eased by washing in medium without drug. After release from the $\mathrm{G}_{2}-\mathrm{M}$ block, cells were collected at different times, and hSWI/SNF was immunoaffinity purified and its activity was measured by determining the effect on the supercoiling of assembled plasmid templates. In parallel, the DN A content of each sample was determined by flow cytometry (Fig. 4A). M ost cells traversed mitosis within 2-3 hr, and after $3 \mathrm{hr}$ cells started to enter $\mathrm{G}_{1}$. A nalysis of the DNA content of cells released from the $\mathrm{G}_{2}-\mathrm{M}$ block reveal ed that by $5 \mathrm{hr}$ 
A

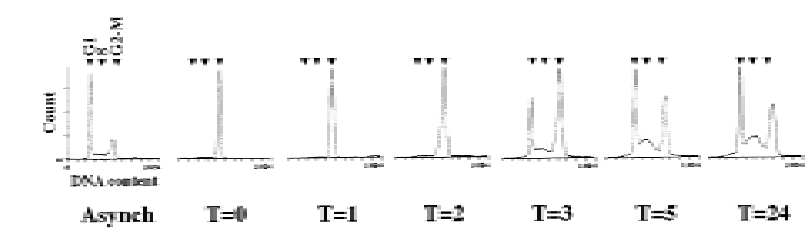

B

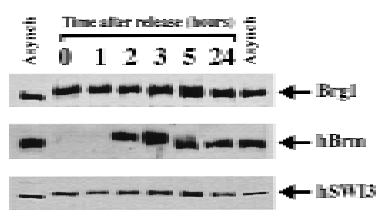

C

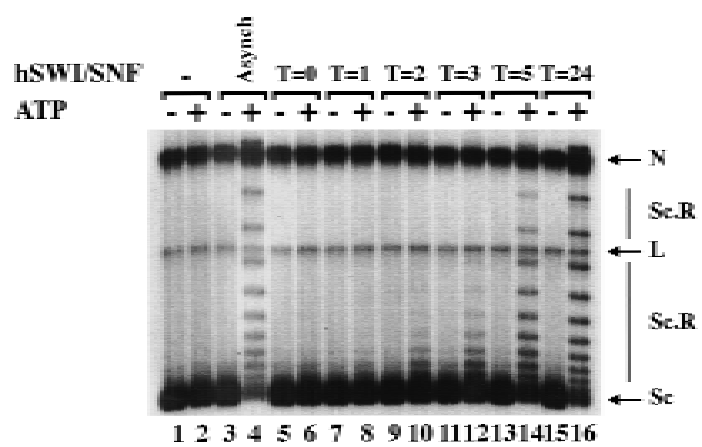

Figure 4. Cell cycle-dependent reactivation of hSWI/SNF complexes. (A) Exponentially growing FL-Inil cells were synchronized in $\mathrm{G}_{2}-\mathrm{M}$ by nocodazole treatment, and then rel eased from the block by washing in medium without drug. Cells were harvested at the indicated times (T), and their DNA content was determined by FACS analysis. For comparison, the DNA content of exponentially growing cells (Asynch) is shown. Small arrowheads indicate the position of each stage of the cell cycle. (B) Cell cycle-dependent dephosphorylation of hSWI/SNF subunits. hSWI/SN F complexes were affinity purified from either asynchronous cells (Asynch), or cells blocked in $\mathrm{G}_{2}-\mathrm{M}$ and then released $(T=0,1,2,3,5$, and 24$)$, and $\mathrm{hSWI} / \mathrm{SN} F$ fractions were then examined for their protein composition and phosphorylation state. A pproximately 200 ng of each fraction was analyzed by Western blotting with either anti-Brgl, anti-hBrm, or antihSWI3. (C) hSWI/SNF reactivation correlates with dephosphorylation of its subunits. Equal amounts (200 ng) of affinitypurified hSWI/SNF fractions from asynchronous cells (lanes $3,4)$, cells blocked in $G_{2}-M$ (lanes 5,6 ), or cells that were released from the block (lanes 7-16) were tested for chromatin remodeling activity by use of an $8 \mathrm{ng}$ assembled template, with or without ATP as indicated. Nicked closed circular (N); linear (L); supercoiled (Sc); and supercoiled and relaxed (Sc.R) plasmid DNA are indicated.

after rel ease, cells began to show a profile that was similar to that of exponentially growing cells.

We also examined the protein levels and phosphorylati on state of Brgl, hBrm, and hSWI 3 for each sample (Fig. 4B), and found that both Brgl and hSWI3 were still phosphorylated 2-3 hr after release from the block. Both proteins appeared to undergo dephosphorylation 3-5 hr after rel ease, and became completely dephosphorylated by
$24 \mathrm{hr}$. hBrm was not detected in the affinity-purified hSWI/SNF fractions until $2 \mathrm{hr}$ after release, at which time it was present and migrated more slowly, consistent with a phosphorylated state (Fig. 4B). The kineti cs of dephosphorylation of hBrm correlated with those of Brgl and hSWI3.

When we tested hSWI/SNF fractions purified from cells blocked in $\mathrm{G}_{2}-\mathrm{M}$, and cells that were released from nocodazole block for activity (Fig. 4C), we found that the complex began to regain chromatin remodeling activity 2-3 hr after release, and was more active by $5 \mathrm{hr}$. The activity of hSWI/SN F at 5 and $24 \mathrm{hr}$ after release was comparable with that of the purified complex from asynchronous cells. Moreover, the ability of the hSWI/SN F complex to remodel chromatin correlated with dephosphorylation of Brgl, hBrm, and hSWI3. These data show that $\mathrm{hSWI} / \mathrm{SN} \mathrm{F}$ is reactivated as cells leave mitosis and enter interphase, and that blocking FL-Inil cells with nocodazole did not result in an irreversible modification of hSWI/SN F complexes.

hSWI/SNF complex is inactivated in vitro by ERK1 and reactivated by protein phosphatase $2 \mathrm{~A}$

To test whether phosphorylation is the only modification required to inactivate the hSWI/SN F complex, we sought to identify a kinase that can phosphorylate hSWI/ SN F and al ter its activity. Previously, it has been shown that Brgl is phosphorylated in unfertilized Xenopus eggs, which are naturally blocked in metaphase (Stukenberg et al. 1997). Fractionation of Xenopus egg extracts revealed that a singl e peak of activity that can phosphorylate Brgl perfectly cofractionates with ERKI $(T$. Stukenberg, unpubl.).

To determine whether ERK1 can phosphorylate human SWI/SNF subunits, we tested MEK1-activated ERK1 for its ability to phosphorylate the hSWI/SNF complex. We found that wild-type GST-ERK1 can phosphorylate SWI/SN F subunits, whereas a kinase-deficient form of GST -ERK1 cannot (Fig. 5A, lanes 2,3). Furthermore, other well-characterized mitotic kinases such as cdc2-cyclinA, cdc2-cyclinB and polo-like kinase 1, were unable to phosphorylate SWI/SNF subunits (data not shown). When we tested the hSWI/SNF complex that is phosphorylated in vitro by activated GST-ERK1 for its ability to remodel chromatin templates, we found that it was inactive (Fig. 5B, lane 8); however, when mutant GST -ERK1 (K63M) that lacks kinase activity was used, hSWI/SNF was still able to remodel assembled templates in an ATP-dependent manner (Fig. 5B, lane 9). In addition, inhibition of hSWI/SNF activity depended on the presence of wild-type GST-ERK1 that is activated by GST-MEK1, and not GST-MEK1, GST-ERK1, or GSTERK1 (K63M) al one (Fig. 5B, lanes 5-7).

Because ERK1 is serine/threonine protein kinase, we wanted to determine whether we could reacti vate hSWI/ SN F efficiently by using a phosphatase that is specific for phosphoserine and phosphothreonine, such as protein phosphatase 2A (PP2A). Active hSWI/SNF was incubated with or without GST-ERK1 and GST-ERK1 

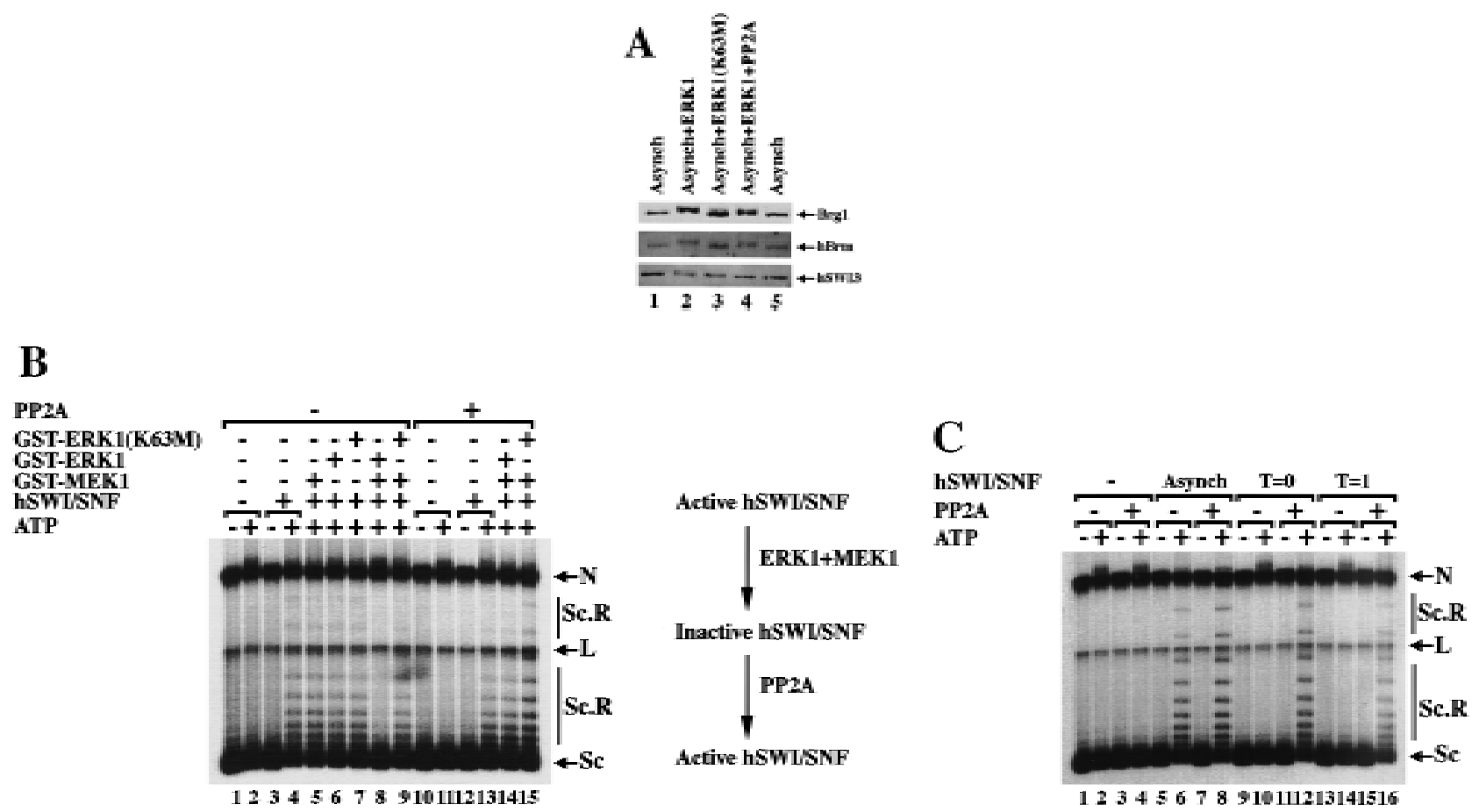

Figure 5. ActivehSWI/SNF is inhibited by ERK1 in vitro. (A) Brgl, hBrm, and hSWI3 are phosphorylated in vitro by GST-ERK1. Equal amounts $(0.75 \mu \mathrm{g} / 15 \mu \mathrm{l}$ reaction) of either wild-type GST -ERK1 or mutant GST-ERK1 (K63M) were activated by GST-His-M EK1 (0.25 $\mu \mathrm{g} / 15 \mu \mathrm{l}$ reaction) as described in M aterials and M ethods. A pproximately $200 \mathrm{ng}$ of asynchronous SWI/SN F was added to the reactions containing either GST -ERK1 (lane 2), or GST-ERK1 (K63M ) (lane 3). Samples were incubated at $30^{\circ} \mathrm{C}$ for $1 \mathrm{hr}$ and anal yzed by Western blotting. When PP2A was added (lane 4), the GST fusion proteins were removed by adding GST beads to the reactions, and the supernatant was incubated with 0.1 units of PP2A at $30^{\circ} \mathrm{C}$ for $1 \mathrm{hr}$. As a control, asynchronous hSWI/SN F subunits are shown (lanes 1,5). (B) hSWI/SN F that is phosphorylated in vitro by ERK1 is inactive. Asynchronous hSWI/SN F fractions were incubated (conditions as in A) with either MEK1-activated or inactive GST-ERK1 and GST-ERK1 (K63M) as indicated. As controls, hSWI/SNF was also tested for activity after incubation with either GST-M EK1 (lane 5), GST-ERK1 (lane 6), or GST-ERK1 (K63M) (Iane 7). When PP2A was added (lanes 10-15), samples were treated as described in A. Assays are performed as in Fig. 4. (C) Brgl-containing complex is efficiently reactivated by PP2A. hSWI/SNF fractions purified from cells growing exponentially (Asynch), cells blocked in $G_{2}-M(T=0)$, or cells bl ocked and then rel eased $(T=1)$, were incubated with supercoiled templates with or without ATP and PP2A as indicated. When PP2A was added, samples were preincubated with 0.1 units of PP2A at $30^{\circ} \mathrm{C}$ for $1 \mathrm{hr}$.

(K63M ), and the GST fusion proteins were then removed by adding glutathione beads to the reactions. The supernatant that contained phosphorylated and inactive hSWI/SN F, was incubated with PP2A, and then either analyzed by Western blotting (Fig. 5A) or tested for activity (Fig. 5B).

Treatment of phosphorylated SWI/SNF with PP2A caused partial dephosphorylation of Brgl and hBrm, and complete dephosphorylation of hSWI3 (Fig. 5A, lane 4). Treatment with PP2A reactivated phosphorylated SWI/ SN F (Fig. 5B, cf. Iane 14 with Iane 8), essentially back to starting levels (Fig. 5B, cf. lane 14 with lane 13). These data show that hSWI/SNF activity can be turned off in vitro with ERK 1 and turned on with PP2A, and therefore show a strong correl ation between SWI/SN F activity and phosphorylation state.

Mitotic and inactive Brgl-containing complex is reactivated by $\mathrm{PP} 2 \mathrm{~A}$

SWI/SN F activity is regained when Brgl and hSWI3 become dephosphorylated either in vitro by alkaline phos- phatase or in vivo as cells exit mitosis (Figs. 3,4). To determine whether the Brgl-containing complex can be reactivated by $P P 2 A$, we examined $h S W I / S N F$ fractions that contain Brgl but not hBrm (Fig. 4B, T =0 and T =1). Following PP2A treatment, both fractions were able to efficiently remodel chromatin templates (Fig. 5C, cf. Ianes 12 and 16 with lanes 10 and 14), suggesting that the Brgl-based complex isolated from cells in mitosis can be fully reactivated by dephosphorylation by PP2A.

\section{Discussion}

We have developed a cell line that can be used to rapidly purify hSWI/SNF complexes to near homogeneity through a two-step purification method. When we examined the activity of hSWI/SNF complexes at different stages of the cell cycle, we found that hSWI/SN F purified from cells blocked in prometaphase is inactive, contains Brgl but not hBrm, and is phosphorylated on Brgl and hSWI3. When this complex was treated in vitro with phosphatase, it regained ATP-dependent remodel ing activity. We have also shown that active hSWI/SN F from 
asynchronous cells can be phosphorylated and inhibited in vitro by ERK1, and that phosphatase treatment of this complex results in its efficient reactivation. These data suggest that hSWI/SNF activity is regulated by phosphorylation as cells traverse mitosis.

Inactivation of hSWI/SN F activity occurs as cells enter mitosis and chromosomes become condensed and many genes become transcriptionally inactive. The nucleosome remodeling activity of SWI/SN F is believed to play a direct role in activating gene expression by increasing transcription factor access to chromatin, and thus inactivation of this complex might be one mechanism of inhibiting gene expression during mitosis. It is also possible that inactivation of this complex is an important step in the process that leads to efficient condensation of chromatin structure. The Brgl-based hSWI/ SN F complex is present at high levels, and the remodeled chromatin state that results from its action might not be a suitable substrate for the proteins that condense chromatin. The observed reversible inactivation of the intact Brgl-based complex is a parsimonious solution to the problem of inactivating remodeling compl exes when chromosomes become condensed and inactive. By keeping this complex intact during mitosis, it is possible that it can be rapidly reactivated when cells exit mitosis and require an active nucleosome remodeling activity to reactive gene expression.

Brgl and hBrm-based hSWI/SNF complexes are regulated differently during mitosis

It is not clear what mechanisms are used in the cell to distinguish the Brgl-based complex from the hBrmbased complex. Both compl exes appear to have very similar if not identical subunit composition, with the only clear difference being the nature of the ATPase associated with the complex. It is clear, however, from both this work and previous work (Muchardt et al. 1996; Wang et al . 1996b) that the two complexes play different roles and are regulated differently in vivo. We have shown that the Brgl-based complex is soluble and intact in cells blocked in $\mathrm{G}_{2}-\mathrm{M}$, and contains all of the subunits characteristic of hSWI/SNF complexes (Fig. 3C). The majority of Brgl protein becomes dephosphorylated $5 \mathrm{hr}$ after cells are released from a nocodazole bock (Fig. 4B; Muchardt et al. 1996). Reactivation of hSWI/SN F activity occurs with the same kinetics as dephosphorylation of the Brgl and hSWI3 proteins in vivo. The reactivation of hSWI/SNF activity is likely to be caused in large part by reactivation of the Brgl-containing complex, as dephosphorylation of fractions that contain only phosphorylated Brgl, and not hBrm, leads to reactivation of ATP-dependent remodeling (Fig. 5C).

The inactivation of the hBrm-based complex, which appears to be targeted for degradation during mitosis, is another mechanism by which cells might inhibit nucleosome remodel ing complexes. Western analysis on whole cells shows that most of the hBrm is degraded in cells blocked in $\mathrm{G}_{2}-\mathrm{M}$, but there remains a small amount that is not soluble (data not shown). The level of $\mathrm{hBrm}$ is restored to normal $2 \mathrm{hr}$ after release from the block, and it is at this time that it becomes detectable in the affinity-purified fractions. The levels of hSWI3 and Ini 1, both of which are components of hBrm complexes, are also reduced slightly during mitosis and increase $2 \mathrm{hr}$ after release from nocodazole block. It appears, therefore, that the hBrm-based complex is targeted for degradation during mitosis.

Regulation of hSWI/SNF activity by phosphorylation and dephosphorylation

It is not known which kinase(s) are responsi ble for phosphorylation of hSWI/SN F subunits as cells enter mitosis, and which phosphatase(s) are required for dephosphorylation later in the cell cycle. Cdc2 is considered to be essential for $\mathrm{G}_{2}$-to-M transition and appears to phosphorylate a wide variety of proteins (Riabowol et al. 1989). Previous work with the Xenopus homolog of human Brgl showed that Xenopus Brgl is phosphorylated during mitosis; however, it is not phosphorylated by cdc2-cyclinB kinase in vitro (Stukenberg et al. 1997). This is in accord with our findings that mitotic kinases such as cdc2-cyclinA, cdc2-cyclinB, and polo-like kinase 1 do not phosphorylate hSWI/SNF subunits.

We have found that active ERK1 can phosphorylate and thus inactivates hSWI/SN F complexes. The involvement of the mitogen-activated protein kinase (MAPK) signal transduction pathway in mitosis is not well understood; however, recently MEK 1 has been shown to be involved in the golgi fragmentation that occurs during mitosis by activating a novel ERK that is associated with the golgi membrane (Acharya et al. 1998). We have shown that ERK1 can inhibit hSWI/SNF activity by phosphorylating Brgl, hBrm, and hSWI3 in vitro, and that these same SWI/SN F subunits are al so phosphorylated in vivo. There are thirteen potential MAPK sites in Brgl, and seven in hSWI3, so it is not clear at this time what portion of these large proteins might be phosphorylated. It is possible that ERK1, or another MAPK with similar substrate specificity, might be involved in regulating hSWI/SNF activity during mitosis; however, it is also possible that other kinases are involved. Further experiments are needed to clarify the role of the MAPK family of proteins in regulating the activity of chromatin remodeling complexes in vivo.

Regulation of hSWI/SN F complexes by phosphorylation leads to their exclusion from condensed chromatin (Muchardt et al. 1996) and to the inactivation of Brglcontaining complexes and degradation of hBrm-based complexes. We do not yet understand the mechanism by which phosphorylation inactivates the Brgl complex. The phosphorylated Brgl complex, which contains all of the SWI/SN F subunits, el utes at a smaller apparent native mol ecular weight than the nonphosphorylated complex on a sizing column (Fig. 3; data not shown). It is possible that phosphorylation causes a conformational change that alters the mobility of the complex, or that there is a monomer-dimer transition of the complex. The FL-Inil cell line that we have developed can be used 
to further define how the characteristics of SWI/SNF change with and without phosphorylation, and how SWI/SN F activity changes as cells traverse the cell cycle.

\section{Materials and methods}

\section{Plasmid constructions}

Plasmic pBabe/FL-Ini 1 for the expression of carboxy-terminalIy Flag-tagged Inil was generated by subcloning the $1.2-\mathrm{kb}$ fragment described bel ow into the unique EcoRI site of the retroviral vector pBabe (M orgenstern and Land 1990). Ini 1 cDN A sequences were obtained by PCR amplification from a human peripheral blood CDNA library (HPB-ALL) by use of two oligonucleotides (5'-CCGGAATTCCCGCCTCTGCCGCCGCAATG-3', and 5'-CGGAATTCCTCATTATTTGTCATCGTCGTCCTTGTAGTCCCAGGCCGGGCCCGTGTTGGCAAGACG-3', Ini 1 sequences are shown in boldface type) containing EcoRI sites, which are specific for the Inil CDNA (nucleotides 52-72 and 1198-1224, respectively, Kal pana et al. 1994). The 3' primer was designed to incorporate a Flag-tagged (DYKDDDDK) sequence before the stop codon of Inil. To generate plasmid pGEX-5cSWI3 for the expression of GST-hSWI3 (amino acids 672-771) fusion protein, a partial human SWI3 (hSWI3) CDNA encoding amino acids 1-808 was isolated by screening the HPB-ALL plasmid library with a 0.68-kb human CDN A probe, which encodes amino acids 424-563 (kindly provided by Alexander Strunnikov and Doug Koshland, Carnegie Institution of Washington). Several clones were isolated and the longest hSWI3 cDNA (2.5 kb) was sequenced and found to be similar but not identical to hSWI3 (BAF155) (Wang et al. 1996a). Using this partial hSWI3 cDNA clone, a 0.36-kb fragment encoding amino acids 672-771 was generated with specific primers, which introduced a BamHI and an EcoRI site at the $5^{\prime}$ and $3^{\prime}$ ends, respectively. The BamHI-EcoRI fragment was subcloned into pGEX-2TK (Pharmacia, Inc.) to generate pGEX5 CSWI3.

\section{Establishment of cell lines expressing FL-Ini 1}

Retroviral expression plasmid pBabe/FL-Ini 1, which contains a puromycin resistance gene, was transfected into the Bing-packaging cell line essentially as described previously (Ausubel et al. 1996). Briefly, $20 \mu \mathrm{g}$ of plasmid DNA was used to transfect $2 \times 10^{6}$ Bing cells by the cal cium phosphate method in the presence of $25 \mu \mathrm{m} / \mathrm{ml}$ chloroquine. M edium containing hel per-free and replication-deficient retrovirus was harvested 48-72 $\mathrm{hr}$ posttransfection, and used to infect $2 \times 10^{6}$ freshly seeded HeLA S3 cells in the presence of $8 \mu \mathrm{g} / \mathrm{ml}$ polybrene. Infected cells were grown in medium containing $2 \mu \mathrm{g} / \mathrm{ml}$ puromycin, and individual colonies were isolated and expanded into cell lines. Four clones that were estimated to express varying levels of FL-Ini 1 were expanded into large volumes of medium containing puromycin at Cellex Biosciences, Inc.

\section{Purification of Flag-tagged hSWI/SNF complexes}

Clone FL-Ini1-11 was used to prepare nuclear extracts as de scribed previously (Dignam et al. 1983; Li et al. 1991). A pproximately $60 \mathrm{mg}$ of nuclear proteins were incubated with $1 \mathrm{ml}$ of anti-Flag M 2 affinity gel (Kodak, Inc.) at $4^{\circ} \mathrm{C}$ for $8-12 \mathrm{hr}$. Beads were then loaded onto a column and washed extensively with buffer BC-0 [20 mm HEPES (pH 7.9), 20\% glycerol, 2 mm EDTA, $1 \mathrm{mM}$ DTT and $0.5 \mathrm{~mm}$ PMSF] supplemented with $0.15 \mathrm{M} \mathrm{KCl}$, followed with a wash with buffer BC-0.3 (BC-0 containing 300 $\mathrm{mm} \mathrm{KCl}$ ). Bound proteins were eluted in $\mathrm{BC}-0$ containing 100 $\mathrm{mM} \mathrm{KCl}(\mathrm{BC}-0.1)$ and a 20 -fold molar excess of Flag peptide (Kodak). The concentration of immunopurified hSWI/SN F complexes was determined by Bradford assay (Bio-Rad), and proteins were analyzed by SDS-PAGE and silver staining as described previously (Kwon et al. 1994). Affinity-purified complexes were then fractionated on a Superose 6 sizing column (Pharmacia). All Superose 6 columns were $40 \mathrm{ml}$, were equilibrated in buffer $\mathrm{BC}-0.1$, and 1-ml fractions were collected.

\section{Cell culture synchronization}

FL-Ini 1 cell lines were grown in Dulbecco's modified Eagle media (DMEM) supplemented with $10 \%$ fetal bovine serum (FBS) until they reached $30 \%-40 \%$ confluence, then they were fed with medium containing either $10 \mathrm{~mm}$ hydroxyurea for $24 \mathrm{hr}$ (S-phase block), or $330 \mathrm{~nm}$ nocodazole for 20-24 hr $\left(\mathrm{G}_{2}-\mathrm{M}\right.$ block). Cells were then collected, washed twice with PBS, and extracts were prepared as described previously (Dignam et al. 1983; Li et al. 1991). When cells were released from the nocodazole block, they were washed with PBS, resuspended in medium without nocodazole and grown at $37^{\circ} \mathrm{C}$ before they were harvested at different times. The DNA content of each sample was determined as described previously (Ausubel et al. 1996).

\section{Nucleosome disruption assays}

A DNA fragment of $\sim 150 \mathrm{bp}$, which contains two copies of a 20-bp artificial nucleosome positioning sequence at one end and a TATA box in the middle, was obtained by digesting plasmid TPT with EcoRI and Mlul (plasmid pTPT, Anthony Imbalzano, unpubl.). The EcoRI-Mlul fragment was ${ }^{32} \mathrm{P}$-labeled and was assembled into a mononucleosomal core particle in the presence of purified HeLa core histones by salt dilution as described (Imbalzano et al. 1994). Assembled templates were purified by glycerol gradient sedimentation and $3.3 \mathrm{ng}$ of nucleosome core particles was incubated with or without ATP and hSWI/SNF fractions in a $25 \mu \mathrm{l}$ reaction containing $12 \mathrm{~mm} \operatorname{HEPES}(\mathrm{pH}$ 7.9), $60 \mathrm{~mm} \mathrm{KCl}, 6 \mathrm{~mm} \mathrm{MgCl} 2,60 \mu \mathrm{M}$ EDTA, 2 mM DTT and 13\% glycerol. Reactions were incubated at $30^{\circ} \mathrm{C}$ for $30 \mathrm{~min}$, treated with DN ase I ( 0.2 units) for $2 \mathrm{~min}$ at room temperature, and analyzed on an $8 \%$ SDS-polyacrylamide-denaturing gel.

\section{Chromatin remodeling assays}

A 2.7-kb plasmid DNA was linearized with EcoRI, treated with alkaline phosphatase, and kinased with T4 polynucleotide kinase. The labeled plasmid DNA was religated and used to reconstitute chromatin templates as described previously (Becker and Wu 1992; Bulger and Kadonaga 1994). Briefly, 1 $\mu \mathrm{g}$ of internally labeled plasmid DN A was incubated with $1.5 \mathrm{mg}$ of S-190 Drosophila embryo extract (Bulger and Kadonaga 1994) and 0.6 $\mu \mathrm{g}$ of HeLa core histones at $27^{\circ} \mathrm{C}$ for $5 \mathrm{hr}$. Reactions were stopped with $0.5 \mathrm{~m}$ EDTA to a final concentration of $20 \mathrm{~mm}$. Assembled chromatin templates were purified by glycerol gradient sedimentation, and incubated for $60-90 \mathrm{~min}$ at $30^{\circ} \mathrm{C}$ with or without ATP and hSWI/SNF fractions in a $25 \mu$ reaction supplemented with wheat germ topoisomerase I (Promega) as described for nucleosome disruption assays. Reactions were then stopped with buffer B [50 mM Tris- $\mathrm{HCl}(\mathrm{pH} 8.0), 0.1 \mathrm{~mm}$ EDTA, 25\% (vol/vol) glycerol, 3\% (wt/ vol) SDS, 0.04\% (wt/ vol) bromophenol blue and $0.04 \%$ (wt/vol) xylene cyanol] supplemented with $2 \mathrm{mg} / \mathrm{ml}$ proteinase $\mathrm{K}$, then were incubated at $37^{\circ} \mathrm{C}$ for $30-40 \mathrm{~min}$ before they were analyzed on a $2 \%$ agarose gel. 


\section{Kinase assays}

Wild-type and mutant GST-ERK1, and their activating kinase, GST-His-MEK1, were prepared as described (Crews et al. 1991, 1992; Huang and Erikson 1994). Both GST-ERK1 and GSTERK1 (K63M) were activated by a constitutively active form of MEK1 in a $15 \mu$ reaction containing kinase buffer [15 mM HEPES (pH 7.5), $15 \mathrm{~mm} \mathrm{MgCl}, 75 \mu \mathrm{g} / \mathrm{ml} \mathrm{BSA}, 1 \mathrm{~mm} \mathrm{ATP]} \mathrm{at}$ $30^{\circ} \mathrm{C}$ for $1 \mathrm{hr}$. Active hSWI/SN F was added to the reactions, and ATP was added to a final concentration of $2 \mathrm{~mm}$. Samples were incubated at $30^{\circ} \mathrm{C}$ for $1 \mathrm{hr}$, and were either added directly to the reactions containing supercoiled templates as described above, or analyzed by Western blotting. When samples were dephosphorylated, GST fusion proteins were removed by adding GST beads that were pre-equilibrated in buffer BC-0.1 to the reactions. Samples were incubated at room temperature for $15 \mathrm{~min}$, and protein phosphatase 2A (CAL Biochem, Inc.) (final concentration of 0.1 units) was added to the supernatant. Samples were incubated at $30^{\circ} \mathrm{C}$ for $1 \mathrm{hr}$, and were either tested for chromatin remodeling activity or analyzed by Western blotting.

\section{Western blotting and antibody production}

Proteins were analyzed by SDS-PAGE, transferred onto a nitrocellulose membrane, and detected by ECL reagents according to the manufacturer's recommendations (A mersham). hSWI3 rabbit polyclonal antiserum was generated by use of GST-hSWI3 fusion protein containing amino acids 672-771. Anti-hBrm rabbit polyclonal antiserum was raised against a peptide that is unique to hBrm (amino acids 282-313). Both anti-hSWI3 and anti-hBrm antibodies were generated by Covance, Inc. Mouse monoclonal anti-Flag M2 and rabbit polyclonal anti-Flag antibodies were purchased from Kodak and Santa Cruz, respectively.

\section{Acknowledgments}

We thank W. Pear, M. Scott, and D. Baltimore for kindly providing the pBabe retroviral vector and Bing cell line, A. Strunnikov and D. Koshland for hSW13 CDN A probe, A. Imbalzano for plasmid TPT and HeLa core histones, J. Hogan and J. A vruch for the GST-His-MEK1 construct, and R. Erikson for plasmids for the expression of wild-type and mutant GST-ERK1. We are grateful to H. Su for technical assistance, Z. Shao, G. Schnitzler, and A. Imbalzano for providing Drosophila embryo extracts and anti-Brgl sera, and M. Hirschel and J. M oquist from Cellex Biosciences, Inc. for growing our cell lines. We thank T. Gilmore, J. Lee, and members of our laboratory for critical reading of the manuscript. This work was supported by $\mathrm{N}$ ational Institutes of Heal th grant GM 48405 to R.E.K. S.S. Was supported by an N IH postdoctoral fellowship.

The publication costs of this article were defrayed in part by payment of page charges. This article must therefore be hereby marked 'advertisement' in accordance with 18 USC section 1734 solely to indicate this fact.

\section{References}

Acharya, U., A. M al labiabarrena, J.K. A charya, and V. Mal hotra. 1998. Signaling via mitogen-activated protein kinase kinase (MEK1) is required for golgi fragmentation during mitosis. Cell 92: 183-192.

Ausubel, F.M., R. Brent, R.E. Kingston, D.D. Moore, J.G. Seidman, J.A. Smith, and K. Struhl. 1996. Current protocols in molecular biology. John Wiley and Sons, N ew York.

Becker, P.B. and C. Wu. 1992. Cell-free system for assembly of transcriptionally repressed chromatin from Drosophila em- bryos. Mol. Cell. Biol. 12: 2241-2249.

Bulger, M. and J.T. Kadonaga. 1994. Biochemical reconstitution of chromatin with physiological nucleosome spacing. Methods Mol. Genet. 14: 241-262.

Cairns, B.R., Y.J. Kim, M.H. Sayre, B.C. Laurent, and R.D. Kornberg. 1994. A multisubunit complex containing the SWI1/ ADR6, SWI2/SNF2, SWI3, SN F5, and SN F6 gene products isolated from yeast. Proc. N atl. Acad. Sci. 91: 1950-1954.

Cairns, B.R., Y. Lorch, Y. Li, M. Zhang, L. Lacomis, H. Erdjument-Bromage, P. Tempst, J. Du, B. Laurent, and R.D. Kornberg. 1996. RSC, an essential, abundant chromatin-remodeling complex. Cell 87: 1249-1260.

Cao, Y., B.R. Cairns, R.D. Kornberg, and B.C. Laurent. 1997. Sfhlp, a component of a novel chromatin-remodeling complex, is required for cell cycle progression. Mol. Cell. Biol. 17: 3323-3334.

Chiba, H., M. M uramatsu, A. N omoto, and H. Kato. 1994. Two human homologues of Saccharomyces cerevisiae SWI2/ SNF2 and Drosophila brahma are transcriptional coactivators cooperating with the estrogen receptor and the retinoic acid receptor. Nucleic Acids Res. 22: 1815-1820.

Côté, J., J. Quinn, J.L. Workman, and C.L. Peterson. 1994. Stimulation of GAL4 derivative binding to nucleosomal DNA by the yeast SWI/SN F complex. Science 265: 53-60.

Crews, C.M., A.A. Alessandrini, and R.L. Erikson. 1991. M ouse Erk-1 gene product is a serine/threonine protein kinase that has the potential to phosphorylate tyrosine. Proc. Natl. Acad. Sci. 88: 8845-8849.

- - . 1992. The primary structure of MEK, a protein kinase that phosphorylates the ERK gene product. Science 258: 478480.

Dignam, J.D., P.L. M artin, B.S. Shastry, and R.G. Roeder. 1983. Eurkaryotic gene transcription with purified components. Methods Enzymol. 101: 582-598.

Dingwall, A.K., S.J. Beek, C.M. M cCallum, J.W. Tamkun, G.V. Kalpana, S.P. Goff, and M.P. Scott. 1995. The Drosophila snr1 and brm proteins are related to yeast SWI/SN F proteins and are components of a large protein complex. Mol. Biol. Cel. 6: 777-791.

Dunaief, J.L., B.E. Strober, S. Guha, P.A. Khavari, K. Alin, J. Luban, M. Begemann, G.R. Crabtree, and S.P. Goff. 1994. The retinoblastoma protein and BRG 1 form a complex and cooperate to induce cell cycle arrest. Cell 79: 119-130.

Dynlacht, B.D. 1997. Regulation of transcription by proteins that control the cell cycle. Nature 389: 149-152.

Gottesfeld, J.M. and D.J. Forbes. 1997. Mitotic repression of the transcriptional machinery. Trends Biochem. Sci. 22: 197202.

Hartl, P., J. Gottesfeld, and D.J. Forbes. 1993. Mitotic repression of transcription in vitro. J. Cell Biol. 120: 613-624.

Huang, W. and R.L. Erikson. 1994. Constitutive activation of Mek1 by mutation of serine phosphorylation sites. Proc. Natl. Acad. Sci. 91: 8960-8963.

Imbalzano, A.N., H. Kwon, M.R. Green, and R.E. Kingston. 1994. Facilitated binding of TATA-binding protein to nucleosomal DN A. Nature 370: 481-485.

Ito, T., M. Bulger, M.J. Pazin, R. Kobayashi, and J.T. Kadonaga. 1997. ACF, an ISWI-containing and ATP-utilizing chromatin assembly and remodeling factor. Cell 90: 145-155.

Kal pana, G.V., S. Marmon, W. Wang, G.R. Crabtree, and S.P. Goff. 1994. Binding and stimulation of HIV-1 integrase by a human homolog of yeast transcription factor SN F5. Science 266: 2002-2006.

Khavari, P.A., C.L. Peterson, J.W. Tamkun, D.B. Mendel, and G.R. Crabtree. 1993. BRG1 contains a conserved domain of the SWI2/SN F2 family necessary for normal mitotic growth 
and transcription. Nature 366: 170-174.

Kingston, R.E., C.A. Bunker, and A.N . Imbalzano. 1996. Repression and activation by multiprotein complexes that alter chromatin structure. Genes \& Dev. 10: 905-920.

Kwon, H., A.N. Imbalzano, P.A. Khavari, R.E. Kingston, and M.R. Green. 1994. Nucleosome disruption and enhancement of activator binding by a human SW1/SNF complex. Nature 370: 477-481.

Laurent, B.C., X. Yang, and M. Carlson. 1992. An essential Saccharomyces cerevisiae gene homologous to SN F2 encodes a helicase-related protein in a new family. Mol. Cell Biol. 12: 1893-1902.

Li, Y., J. Ross, J.A. Scheppler, and B.R. Franza, Jr. 1991. An in vitro transcription analysis of early responses of the human immunodeficiency virus type 1 long terminal repeat to different transcriptional activators. Mol. Cell. Biol. 11: 18831893.

Lüscher, B. and R.N. Eisenman. 1992. Mitosis-specific phosphorylation of the nuclear oncoproteins. Myc and Myb. J. Cell Biol. 118: 775-784.

Martinez-Bal bás, M.A., A. Dey, S.K. Rabindran, K. Ozato, and C. Wu. 1995. Displacement of sequence-specific transcription factors from mitotic chromatin. Cell 83: 29-38.

Morgernstern, J.P. and H. Land. 1990. Advanced mammalian gene transfer: High titre retroviral vectors with multiple drug selection markers and a complementary helper-free packaging cell line. Nucleic Acids Res. 18: 3587-3596.

Muchardt, C. and M. Yaniv. 1993. A human homologue of Saccharomyces cerevisiae SNF2/SWI2 and Drosophila brm genes potentiates transcriptional activation by the glucocorticoid receptor. EMBO J. 12: 4279-4290.

Muchardt, C., J.C. Reyes, B. Bourachot, E. Leguoy, and M. Yaniv. 1996. The hbrm and BRG-1 proteins, components of the human SNF/SWI complex, are phosphorylated and excluded from the condensed chromosomes during mitosis. EMBO J. 15: 3394-3402.

N asmyth, K. 1996. Viewpoint: Putting the cell cycle in order. Science 274: 1643-1645.

Paranjape, S.M., R.T. Kamakaka, and J.T. Kadonaga. 1994. Role of chromatin structure in the regulation of transcription by RN A polymerase II. Annu. Rev. Biochem. 63: 265-297.

Peterson, C.L., A. Dingwall, and M.P. Scott. 1994. Five SWI/ SN F gene products are components of a large multisubunit complex required for transcriptional enhancement. Proc. Natl. Acad. Sci. 91: 2905-2908.

Reyes, J.C., C. Muchardt, and M. Yaniv. 1997. Components of the human SWI/SN F complex are enriched in active chromatin and are associated with the nuclear matrix. J. Cell Biol. 137: 263-274.

Riabowol, K., G. Dretta, L. Brizuela, D. Vandre, and D. Beach. 1989. The cdc2 kinase is a nuclear protein that is essential for mitosis in mammalian cells. Cell 57: 393-401.

Segil, N., M. Guermah, A. Hoffmann, R.G. Roeder, and N. Heintz. 1996. Mitotic regulation of TFIID: Inhibition of activator-dependent transcription and changes in subcellular localization. Genes \& Dev. 10: 2389-2400.

Strober, B.E., J.L. Dunai ef, S. Guha, and S.P. Goff. 1996. Functional interactions between the hBRM/hBRG1 transcriptional activators and the pRB family of proteins. Mol. Cell Biol. 16: 1576-1583.

Stukenberg, P.T., K.D. Lustig, T.J. McGarry, R.W. King, J. Kuang, and M.W. Kirschner. 1997. Systematic identification of mitotic phosphoproteins. Curr. Biol. 7: 338-348.

Sumi-Ichinose, C., H. Ichinose, D. Metzger, and P. Chambon. 1997. SN F2 $\beta-B R G 1$ is essential for the viability of F9 murine embryonal carcinoma cells. Mol. Cell. Biol. 17: 5976-5986.
Tamkun, J.W., R. Deuring, M.P. Scott, M. Kissinger, A.M. Pattatucci, T.C. Kaufman, and J.A. Kennison. 1992. brahma: A regulator of Drosophila homeotic genes structurally related to the yeast transcriptional activator SNF2/SWI2. Cell 68: $561-572$.

Tsukiyama, T. and C. Wu. 1995. Purification and properties of an ATP-dependent nucleosome remodeling factor. Cell 83: 1011-1020.

Varga-Weiz, P.D., M. Wilm, E. Bonte, K. Dumas, M. Mann, and P.B. Becker. 1997. Chromatin-remodelling factor CHRAC contains the ATPases ISWI and topoisomerase II. Nature 388: 598-602.

Wang, W., Y. Xue, S. Zhou, A. Kuo, B.R. Cairns, and G.R. Crabtree. 1996a. Diversity and specialization of mammalian SWI/SN F complexes. Genes \& Dev. 10: 2117-2130.

Wang, W., J. Côté, Y. Xue, S. Zhou, P.A. Khavari, S.R. Biggar, C. Muchardt, G.V. Kal pana, S.P. Goff, M. Yaniv, J.L. Workman, and G.R. Crabtree. 1996b. Purification and biochemical heterogeneity of the mammalian SWI-SN F complex. EMBO J. 15: 5370-5382.

White, R.J., T.M. Gottlieb, C.S. Downes, and S.P. Jackson. 1995. Mitotic regulation of a TATA-binding protein-containing complex. Mol. Cell. Biol. 15: 1983-1992.

Winston, F. and M. Carlson. 1992. Yeast SNF/SWI transcriptional activators and the SPT/SIN chromatin connection. Trends Genet. 8: 387-391.

Zhou, Z., P.M. Lieberman, T.G. Boyer, and A.J. Berk. 1992. Holo-TFIID supports transcriptional stimulation by diverse activators and from a TATA-less promoter. Genes \& Dev. 6: 1964-1974. 


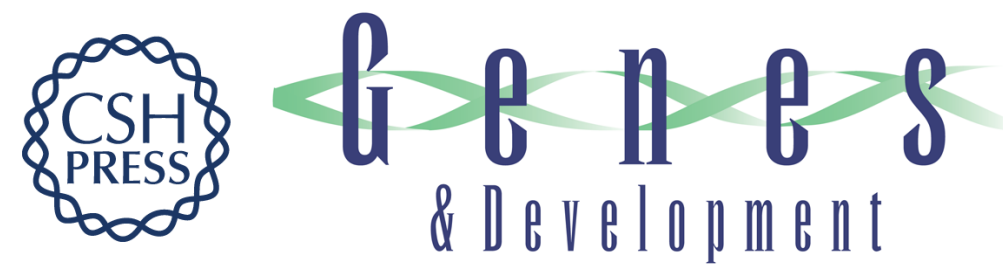

\section{Mitotic inactivation of a human SWI/SNF chromatin remodeling complex}

Saïd Sif, P. Todd Stukenberg, Marc W. Kirschner, et al.

Genes Dev. 1998, 12:

Access the most recent version at doi:10.1101/gad.12.18.2842

References This article cites 47 articles, 23 of which can be accessed free at: http://genesdev.cshlp.org/content/12/18/2842.full.html\#ref-list-1

License

Email Alerting

Service

Receive free email alerts when new articles cite this article - sign up in the box at the top right corner of the article or click here.

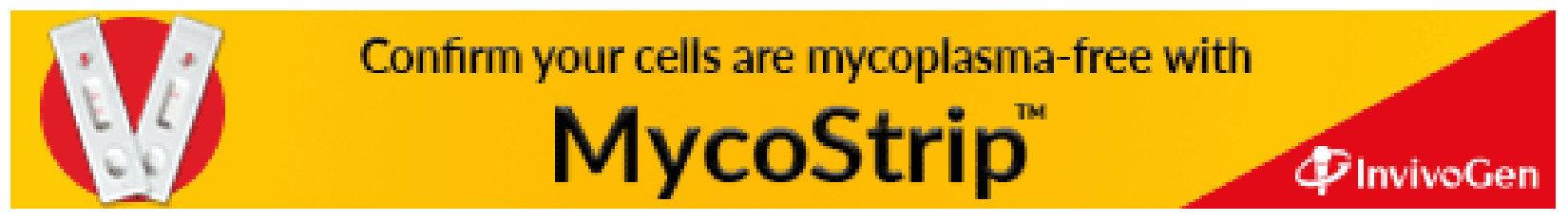

